\title{
QUEEN'S
UNIVERSITY
BELFAST
}

\section{Characterisation and constitutive modelling of biaxially stretched poly(L-lactic acid) sheet for application in coronary stents}

Blair, R. W., Dunne, N. J., Lennon, A. B., \& Menary, G. H. (2019). Characterisation and constitutive modelling of biaxially stretched poly (L-lactic acid) sheet for application in coronary stents. Journal of Mechanical Behavior of Biomedical Materials. https://doi.org/10.1016/j.jmbbm.2019.05.039

Published in:

Journal of Mechanical Behavior of Biomedical Materials

Document Version:

Peer reviewed version

Queen's University Belfast - Research Portal:

Link to publication record in Queen's University Belfast Research Portal

\section{Publisher rights}

Copyright 2019 Elsevier.

This manuscript is distributed under a Creative Commons Attribution-NonCommercial-NoDerivs License

(https://creativecommons.org/licenses/by-nc-nd/4.0/), which permits distribution and reproduction for non-commercial purposes, provided the author and source are cited.

\section{General rights}

Copyright for the publications made accessible via the Queen's University Belfast Research Portal is retained by the author(s) and / or other copyright owners and it is a condition of accessing these publications that users recognise and abide by the legal requirements associated with these rights.

Take down policy

The Research Portal is Queen's institutional repository that provides access to Queen's research output. Every effort has been made to ensure that content in the Research Portal does not infringe any person's rights, or applicable UK laws. If you discover content in the Research Portal that you believe breaches copyright or violates any law, please contact openaccess@qub.ac.uk. 


\section{Accepted Manuscript}

Characterisation and constitutive modelling of biaxially stretched poly(L-lactic acid) sheet for application in coronary stents

R.W. Blair, N.J. Dunne, A.B. Lennon, G.H. Menary

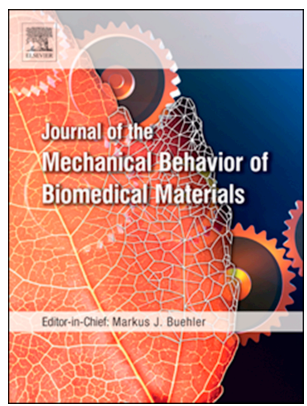

PII:

S1751-6161(18)31699-0

DOI: https://doi.org/10.1016/j.jmbbm.2019.05.039

Reference:

JMBBM 3305

To appear in: Journal of the Mechanical Behavior of Biomedical Materials

Received Date: 5 December 2018

Revised Date: 22 May 2019

Accepted Date: 23 May 2019

Please cite this article as: Blair, R.W., Dunne, N.J., Lennon, A.B., Menary, G.H., Characterisation and constitutive modelling of biaxially stretched poly(L-lactic acid) sheet for application in coronary stents, Journal of the Mechanical Behavior of Biomedical Materials (2019), doi: https://doi.org/10.1016/ j.jmbbm.2019.05.039.

This is a PDF file of an unedited manuscript that has been accepted for publication. As a service to our customers we are providing this early version of the manuscript. The manuscript will undergo copyediting, typesetting, and review of the resulting proof before it is published in its final form. Please note that during the production process errors may be discovered which could affect the content, and all legal disclaimers that apply to the journal pertain. 
1 Characterisation and constitutive modelling of biaxially stretched poly(L-

2 lactic acid) sheet for application in coronary stents

3 R.W. Blair ${ }^{\mathrm{a},{ }^{*},}$, N.J. Dunne ${ }^{\mathrm{b}, c, \mathrm{~d}, \mathrm{e}}$, A.B. Lennon ${ }^{\mathrm{a}}$, G.H. Menary ${ }^{\mathrm{a}}$

$4{ }^{a}$ School of Mechanical and Aerospace Engineering, Queen's University, BT9 5AH, Belfast, UK

$5 \quad{ }^{b}$ School of Mechanical and Manufacturing Engineering, Dublin City University, Dublin 9, Ireland

$6{ }^{c}$ Centre for Medical Engineering Research, School of Mechanical and Manufacturing Engineering,

7 Dublin City University, Dublin 9, Ireland

$8{ }^{d}$ School of Pharmacy, Queen's University, Belfast, BT9 7BL, UK

$9{ }^{e}$ Trinity Centre for Bioengineering, Trinity College Dublin, Dublin 2, Ireland

10 Abstract

11 A poly(L-lactic acid) stent is exposed to a variety of processing techniques, temperatures and environmental conditions during its lifecycle, from the manufacturing process, to crimping through to deployment within the body. The effect of the biaxial stretching procedure and the effects of temperature and extension rate (post-processing) on the mechanical response of poly(L-lactic acid) are hereby investigated, and a constitutive model calibrated against experimental data is proposed. Dumb-bell specimens were punched from biaxially stretched sheets subjected to different processing histories, and tested under uniaxial tension at various temperatures $\left(20,37\right.$ and $\left.55^{\circ} \mathrm{C}\right)$ and extension rates $(1,5$ and $10 \mathrm{~mm} / \mathrm{min})$. A Design of Experiments methodology was employed to identify the parameters that had the most significant effect on the mechanical response of the polymer. Results show that the elastic modulus and yield strength of the stretched sheets are strongly dependent on the aspect ratio of the biaxial deformation, along with the temperature during uniaxial deformation (post-processing). In contrast, these mechanical properties were not heavily dependent on extension rate (post-processing). A transversely isotropic, elastic-plastic constitutive model for finite element implementation is proposed, with the intention that it may be used as a design tool for developing high stiffness, thin-strut polymeric stents that contend with the performance of their metallic counterparts. 


\section{Introduction}

30

Coronary heart disease (CHD) is the largest cause of death in the world, with an estimated 9.4 million people dying from this disease in 2016 (World Health Organization, 2017). It is commonly caused by atherosclerosis, in which fatty deposits (atheroma) develop on the arterial wall causing the artery to harden and narrow (Ross, 1999). Percutaneous coronary intervention (PCI) is the most commonly employed revascularisation technique used in the treatment of narrowed arteries (Ui et al., 2005), in which a small expandable scaffold (stent) is deployed at the site of an atherosclerotic lesion in order to dilate the artery and restore patency. The total number of annual PCls has increased each year since 1991 (Ludman and Gavalova, 2016) and with the ageing of the world population (World Health Organization, 2012), the incidence and economic burden of heart disease is likely to continue increasing.

Whilst $\mathrm{PCl}$ is considered as the most successful non-invasive surgical interventions for the treatment of CHD, with survival rates in excess of $95 \%$ at 10 years (Ludman and Gavalova, 2016), late stent thrombosis (> 1 year) (LST) remains a serious issue for both drug-eluting stents (DES) and bare-metal stents (BMS) (Tada et al., 2013). More recently, there has been a shift in focus to the development of bioresorbable polymer stents, which offer a clinically attractive solution by providing a temporary scaffold that resorbs once the artery has healed, potentially mitigating the risk of LST. Bioresorbable stents offer considerable advantages over both BMS and DES, such as late luminal gain after the stent resorbs, fewer complications during revascularisation procedures and potential paediatric applications (Alexy and Levi, 2013; Brie et al., 2016; Serruys et al., 2011). Poly(L-lactic acid) (PLLA) has shown particular success as the platform material of bioresorbable stents with the Absorb GT1 bioresorbable vascular scaffold (BVS) (Abbott Vascular, Santa Clara, California) and the DESolve ${ }^{\circledR}$ stent (Elixir Medical Corporation, Sunnyvale, California) holding the Conformité Européenne (CE) mark for use in coronary applications (Wiebe et al., 2014). 
Computational modelling is commonly used as a preclinical testing tool to refine and optimise stent geometry, in order to improve the safety and efficacy of these devices (Lally et al., 2005). The U S Food and Drug Administration recommends that computational modelling studies should be presented to support medical device submissions (U S Food and Drug Administration, 2016) and specifically recommends that mechanical properties of the platform material be presented, along with the corresponding constitutive model, that describes how the material responds to various loadings through the use of equations that link the states of stress and strain (Ottosen and Ristinmaa, 2005; U S Food and Drug Administration, 2010). The mechanical response of PLLA depends on temperature, environment and processing (Bobel et al., 2016; Grabow et al., 2005; Lim et al., 2008; Løvdal et al., 2015). However, constitutive models that accurately represent this complex mechanical response of PLLA (prior to degradation) are relatively scarce in the literature, with many studies focusing on modelling the long-term response ( $>1$ year) of the polymer as it degrades (Hayman et al., 2014; Khan and El-Sayed, 2013; Muliana and Rajagopal, 2012; Soares et al., 2008). Whilst modelling the long-term response of the polymer is essential, one of the primary issues with the current generation of bioresorbable stents is stent fracture during deployment and the stent having insufficient radial strength to resist the compressive force of the artery, both of which may be considered to be short-term (pre-degradation) phenomena (Brie et al., 2016; Bourantas et al., 2013).

A summary of published constitutive models developed to capture the short-term response of the polymer is presented in Table 1; each model captures one or more of the rate-dependent, temperature-dependent and anisotropic properties of PLLA. Simplistic constitutive models, such as metal plasticity, in which the mechanical response is independent of direction, strain rate, or temperature may no longer be appropriate for polymeric stents, due to the anisotropy induced in the material during processing and the proximity of the glass transition temperature $\left(T_{\mathrm{g}}\right)$ of the polymer to its service temperatures (Bergström and Hayman, 2015). This was evident from the study by Schultze et al. (2009), in which an elastic-plastic constitutive model significantly over-predicted 
the radial strength of three polymeric bioresorbable stents by approximately $30-100 \%$, when compared against experimental collapse test results.

Table 1. Summary of capabilities of published constitutive models developed to capture important effects for simulating the short-term (pre-degradation) mechanical response of PLLA.

\begin{tabular}{lccc}
\hline Author & Strain rate & Temperature & Anisotropy \\
\hline Debusschere et al. (2015) & Yes & No & No \\
Wang et al. (2017) & No & Yes & No \\
Pauck and Reddy (2015) & No & No & Yes \\
Bobel and McHugh (2018) & Yes & Yes & No \\
Eswaran et al. (2011) & Yes & No & Yes \\
\hline
\end{tabular}

83

84 The temperature-dependent mechanical response of PLLA has been evaluated by Bobel et al. (2016); they observed a reduction in yield strength, coupled with a shift to rubber-like behaviour as the temperature was increased from $20{ }^{\circ} \mathrm{C}$ to $42{ }^{\circ} \mathrm{C}$. Wang et al. (2017) performed tensile testing on PLLA tubes at $37^{\circ} \mathrm{C}$ and $48{ }^{\circ} \mathrm{C}$ (representative of body temperature and the temperature at which a stent is crimped, respectively) and observed a reduction in yield strength of $14 \%$. A temperaturedependent constitutive model was calibrated to experimental data and used in a finite element model to compare the radial strength of a stent against an in vitro test, predicting the radial strength to within $6 \%$. This represented a significant improvement to Schultze et al. (2009), which may be attributed to the inclusion of the crimping procedure and the temperature-dependent mechanical response of PLLA.

Poly(L-lactic acid) has been shown to exhibit a rate-dependent response, with yield strength increasing with strain rate during uniaxial tensile testing (Bobel et al., 2016; Eswaran et al., 2011). Debusschere et al. (2015) calibrated a viscoplastic model of PLLA to uniaxial tensile test data at different strain rates (i.e. $0.1,1$ and $10 \mathrm{~mm} / \mathrm{min}$ ) at body temperature and showed that expanding a 
stent gradually reduced the build-up of internal stresses and consequently reduced the likelihood of fracture during deployment.

The processing history of a PLLA stent typically consists of an initial extrusion into a thick-walled tube (parison), followed by a stretch blow moulding (SBM) process whereby the parison is heated above its $T_{g}$ and a biaxially stretched to create a thin-walled tube. This process of biaxial deformation has been shown to improve the yield strength, elastic modulus, and elongation to failure of PLLA (Wu et al., 2013), all of which are highly desirable properties for coronary stents. The SBM process imposes a state of biaxial strain on the polymer, which often results in different material properties in the circumferential (hoop) and axial directions. This anisotropy has been observed by Eswaran et al. (2011) who calibrated a viscoplastic model of PLLA to specimens punched from PLLA tubing in the hoop and axial directions, noting that specimens punched from the hoop direction exhibited higher yield strength and strain-hardened post-yield. Pauck and Reddy (2015) reported an increase in elastic modulus and yield strength of $40 \%$ and $15 \%$, respectively, when comparing the hoop direction to axial direction at room temperature and an increase of $20 \%$ and $3 \%$, respectively, at body temperature. They refined the geometry of three conventional bioresorbable stent geometries using an anisotropic constitutive model and hypothesised that stent performance may be improved by optimising material processing and correctly matching the geometry to the material.

Comprehensive mechanical characterisation has been performed for PLLA in order to calibrate constitutive models that capture the (i) anisotropy as a result of the processing history (Pauck and Reddy, 2015); (ii) temperature-dependent behaviour (Wang et al., 2017); and (iii) rate-dependent behaviour (Debusschere et al., 2015). However, to the best of the authors' knowledge, the interdependencies between processing history, temperature and extension rate have not been evaluated experimentally and, hence, a representative constitutive model does not exist. The aim of the present study is to experimentally evaluate the effect of temperature and extension rate on the short-term (pre-degradation) mechanical and viscoelastic properties of biaxially stretched PLLA 
of high stiffness, thin strut polymeric stents for the application of coronary stents.

\section{Material and methods}

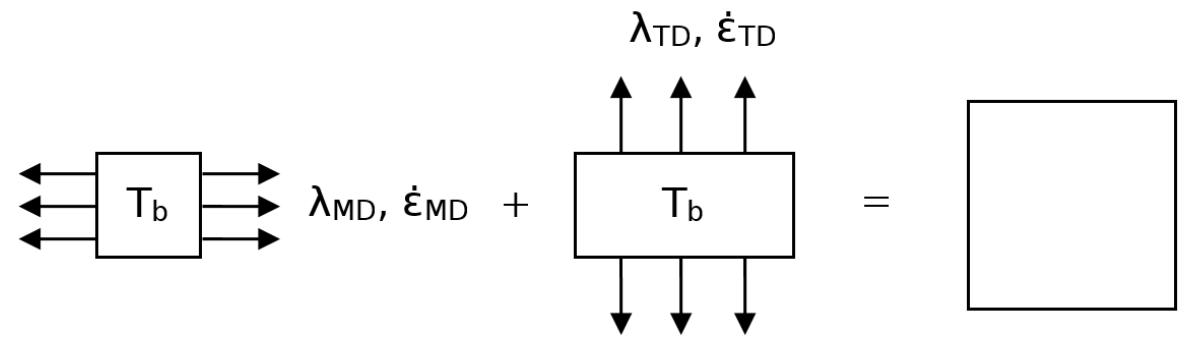

The strain history achieved during SBM was replicated using a custom-built biaxial stretching machine (Martin et al., 2005). Pellets of PLLA (Tradename: Plurapol LX175), containing < 5\% Disomer, were donated by Corbion Purac (The Netherlands) and extruded as per Blair et al. (2018) to yield sheet with a weight-average molecular weight and a polydispersity index of $230 \mathrm{~kg} \mathrm{~mol}-1$ and

2.0, respectively. Poly(L-lactic acid) samples, each with dimensions of $76 \mathrm{~mm} \times 76 \mathrm{~mm} \times 1 \mathrm{~mm}$ were prepared for biaxial stretching. Biaxial deformation was performed using a sequential deformation mode (Fig. 1), with specimens initially undergoing constant width deformation in the machine direction (MD), followed by a second (constant width) deformation in the transverse direction (TD). Specimens were heated to a temperature $\left(T_{b}\right)$ of $80^{\circ} \mathrm{C}$ for $3 \mathrm{~min}$, and deformed at a speed of $16 \mathrm{~s}^{-1}$ in the MD $\left(\dot{\varepsilon}_{\mathrm{MD}}\right)$ and the TD $\left(\dot{\varepsilon}_{\mathrm{TD}}\right)$. The aforementioned conditions provided the most repeatable deformation during biaxial tensile testing, based on a previous study (Blair et al., 2018). In this study, in which the stretch ratio in the MD $\left(\lambda_{\mathrm{MD}}\right)$ and the stretch ratio in the TD $\left(\lambda_{\mathrm{TD}}\right)$, along with the aspect ratio $\left(A_{r}\right)$ between the pair, defined as the ratio of $\lambda_{T D}$ to $\lambda_{M D}$ (Eq. 1), were shown to have the most significant effect on the elastic modulus $(E)$ and yield strength $\left(\sigma_{Y}\right)$ of the polymer.

Fig. 1. Sequential biaxial deformation technique used to replicate SBM processing history. 


$$
A_{r}(-)=\frac{\lambda_{T D}}{\lambda_{M D}}
$$

Dynamic mechanical analysis (DMA) was conducted on the biaxially stretched sheet to evaluate the $T_{g}$ and the storage modulus ( $E^{\prime}$ ) of PLLA as a function of frequency (f) using a Tritec 2000 DMA (Triton Technology Ltd., UK), running Tritec 2000 DMA version 1.43 .00 software. Samples of $10 \mathrm{~mm} \times 4 \mathrm{~mm}$ (length $\mathrm{x}$ width) were punched from biaxially stretched sheet in the MD and the TD. Testing was performed under tension configuration, with all samples having a thickness of $<1 \mathrm{~mm}$. Temperature scans were performed at a heating rate of $5{ }^{\circ} \mathrm{C} / \mathrm{min}$ between the limits of 20 and $130{ }^{\circ} \mathrm{C}$, at frequencies of $0.1,1$ and $10 \mathrm{~Hz}$. These DMA frequencies were selected to induce strain rates in the specimen comparable to those induced during polymeric stent expansion $\left(10^{-4}-10^{-1} \mathrm{~s}^{-1}\right)$ (Bobel et al., 2016). The $T_{g}$ was identified by the onset of the drop in $E^{\prime}$. Frequency scans were performed between the limits of 0.1 and $10 \mathrm{~Hz}$ at room temperature $\left(20 \pm 3.0^{\circ} \mathrm{C}\right)$, body temperature $\left(37 \pm 3.0^{\circ} \mathrm{C}\right.$ ) and a crimping temperature $\left(55 \pm 3.0^{\circ} \mathrm{C}\right)$, which was selected based on the results of the temperature scans presented in the following section. A dynamic displacement of $0.005 \mathrm{~mm}$ was used for all tests, with preliminary testing performed to ensure that the linear viscoelastic regime of the polymer was not exceeded.

A Design of Experiments (DOE) approach was employed to identify the biaxial stretching processing parameters and post-processing uniaxial tensile test conditions that most significantly affect the elastic modulus of PLLA in the MD and TD ( $E_{M D}$ and $E_{T D}$ ) and the yield strength in the MD and the TD $\left(\sigma_{Y, M D}\right.$ and $\left.\sigma_{Y, T D}\right)$. A three-level, three factor, full factorial $\left(3^{3}\right)$ randomised design was used with the following factors: the $A_{r}$ of the biaxial deformation, temperature during uniaxial deformation, and extension rate during uniaxial deformation. The temperature and extension rate during uniaxial deformation refer to post-processing conditions, hereafter referred to as post-processing temperature $(T)$ and post-processing extension rate $(\dot{e})$, and are not to be misinterpreted as the temperature and extension rate applied during biaxial deformation. Preliminary testing was performed to identify upper and lower limits for the parameters evaluated under the DOE (Table 2). 
The $A_{r} s$ of the biaxial deformation were selected to induce varying degrees of anisotropy based on the results from the previous study by Blair et al. (2018). Specifically, $3 \times 3\left(\lambda_{M D} \times \lambda_{T D}\right)$ equibiaxial deformation $\left(A_{r}=1.0\right), 2 \times 3$ asymmetrical deformation $\left(A_{r}=1.5\right)$ and $1.5 \times 3.5$ highly asymmetrical deformation $\left(A_{r}=2.3\right)$ were selected. It should be noted that for each of these $A_{r} s$, the value of either $\lambda_{M D}, \lambda_{I D}$ or both, is greater than 2, as this has been shown to be the critical level of

equibiaxially stretched sample $\left(A_{r}=1\right)$.

The uniaxial tensile properties (i.e. $E$ and $\sigma_{\mathrm{Y}}$ ) of the biaxially stretched sheet was determined in accordance with ISO 527-2 Type 1BA (ISO, 1996) using an Instron 5564 Universal Material Testing machine (Instron, UK). The samples tested $(n=3)$ were dumb-bell in shape; samples were punched from biaxially stretched sheet in the MD and the TD. Uniaxial tensile testing was performed under room temperature $\left(20 \pm 3.0^{\circ} \mathrm{C}\right)$, body temperature $\left(37 \pm 3.0^{\circ} \mathrm{C}\right)$ and a crimping temperature (55 $\pm 3.0^{\circ} \mathrm{C}$ ), using a 3119 Series Instron Environmental Chamber (Instron, UK). The values of è selected were 1,5 and $10 \mathrm{~mm} / \mathrm{min}$, based on the recommended deformation speeds for polymeric stent expansion (Abbott, 2012). Multiple regression analysis was performed on the results using $R$ (version 3.4.0) (R Core Team, 2017) to provide an empirical correlation between the factors included in the DOE and the mechanical properties of the stretched PLLA sheet.

Table 2. High, medium and low levels for the aspect ratio $\left(A_{r}\right)$ of the biaxial deformation, postprocessing temperature $(\mathrm{T})$ and post-processing extension rate $(\dot{\mathrm{e}})$ evaluated under the DOE.

\begin{tabular}{ccc}
\hline $\boldsymbol{A}_{\boldsymbol{r}}$ & $\boldsymbol{T}$ & $\dot{\boldsymbol{e}}$ \\
\hline$(-)$ & $\left({ }^{\circ} \mathrm{C}\right)$ & $(\mathbf{m m} / \mathbf{m i n})$ \\
\hline 1.0 & 20 & 1 \\
1.5 & 37 & 5 \\
2.3 & 55 & 10 \\
\hline
\end{tabular}


188

\section{Experimental results}

The results from the DMA studies (Fig. $2 \mathrm{a}$ and Fig. $2 \mathrm{~b}$ ) indicated there is a statistically significant relationship $(p<0.05)$ between the $T_{\mathrm{g}}$ and $\mathrm{f}$ for samples taken from biaxially stretched PLLA sheet in both the MD and the TD. However, no such relationship was found between the $T_{g}$ and $A_{r}$, based on the results of two-way analysis of variance (ANOVA). A two-sample t-test showed no significant statistical difference $(p>0.05)$ between the $\mathrm{T}_{\mathrm{g}}$ in the MD and the TD. Abbott's patented method for crimping a polymeric stent onto a delivery balloon (Jow et al., 2017) states that the stent is to be crimped at a temperature between the $T_{\mathrm{g}}$ and $15{ }^{\circ} \mathrm{C}$ below the $T_{\mathrm{g}}$. The $\mathrm{T}_{\mathrm{g}}$ ranged from $60.8-69.2{ }^{\circ} \mathrm{C}$ for all samples tested in this study. Therefore, $55{ }^{\circ} \mathrm{C}$ was used as a representative crimping temperature for the DOE.

(a) Machine direction (MD)

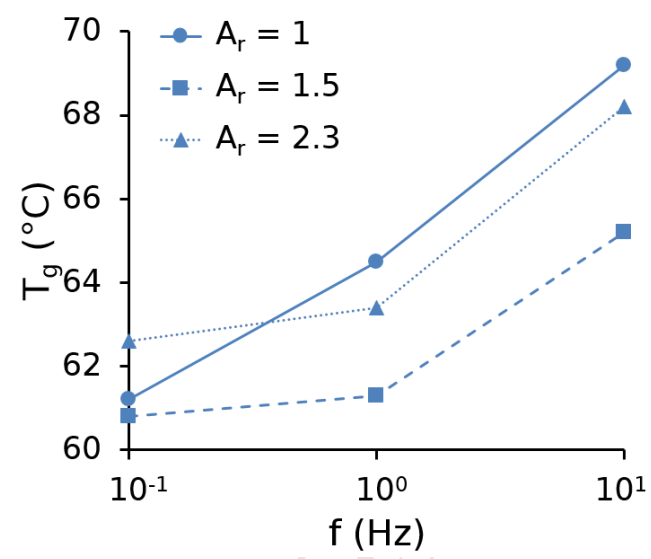

(b) Transverse direction (TD)

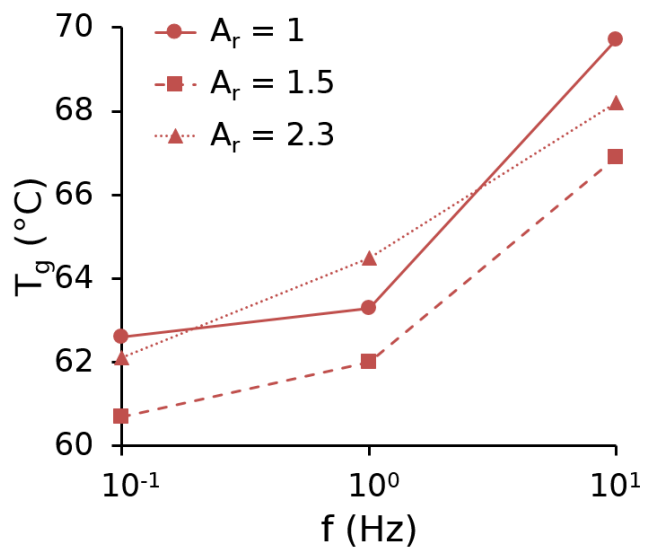

Fig. 2. Glass transition temperature $\left(T_{g}\right)$ at a given frequency $(f)$ and aspect ratio $\left(A_{r}\right)$ for biaxially stretched PLLA sampled from (a) the machine direction (MD) and (b) the transverse direction (TD).

The main effect plots from the DOE study (Fig. 3a and Fig. 3b) describe the effect of each factor on each response variable (i.e. $E_{M D}, E_{T D}, \sigma_{Y, M D}$ and $\sigma_{Y, T D}$ ), independent of all other factors. The steeper the slope of the line between factor levels, the greater the magnitude of the effect; the dotted line for each response variable represents the mean value across all runs. In general, $E$ and $\sigma_{\mathrm{Y}}$ are most strongly affected by $A_{r}$ and $T$, with è having a relatively weaker effect. Furthermore, increases in $E_{T D}$ 
and $\sigma_{Y, T D}$ are obtained by increasing the $A_{r}$ beyond unity $\left(A_{r}>1\right)$, however this comes at the expense of a reduction in $\mathrm{E}_{\mathrm{MD}}$ and $\sigma_{\mathrm{Y}, \mathrm{MD}}$.

The two-way interaction plots from the DOE (Fig. 4a-d) describe the dependency of one factor on the level of another factor for each response variable. The more parallel the lines on the plots, the weaker the interaction, whilst the more non-parallel the lines, the stronger the interaction. Analysis of variance was conducted to determine main factors and interactions that were statistically significant $(p<0.05)$, whilst multiple regression analysis of the results was performed to generate constitutive equations (Eq. 2-5). Results showed that for each response variable, $A_{r}$ and $T$ terms were statistically significant $(p<0.05)$, whilst è terms and all interaction terms were not statistically significant $(p>0.05)$, with Eq. $2-5$ achieving adjusted $R$-squared $\left(R^{2}\right.$ adj $)$ values of $0.79,0.86,0.85$ and 0.93 , respectively.

$$
\begin{gathered}
E_{M D}=3869-433 A_{r}-36 T \\
E_{T D}=3501+610 A_{r}-50 T \\
\sigma_{Y, M D}=90-8.3 A_{r}-T \\
\sigma_{Y, T D}=90+7.3 A_{r}-1.3 T
\end{gathered}
$$

217

218 Results of the DMA frequency sweeps showed that the storage modulus ( $E^{\prime}$ ) remained relatively never exceeding $3.4 \%$ (Table 3 ). 


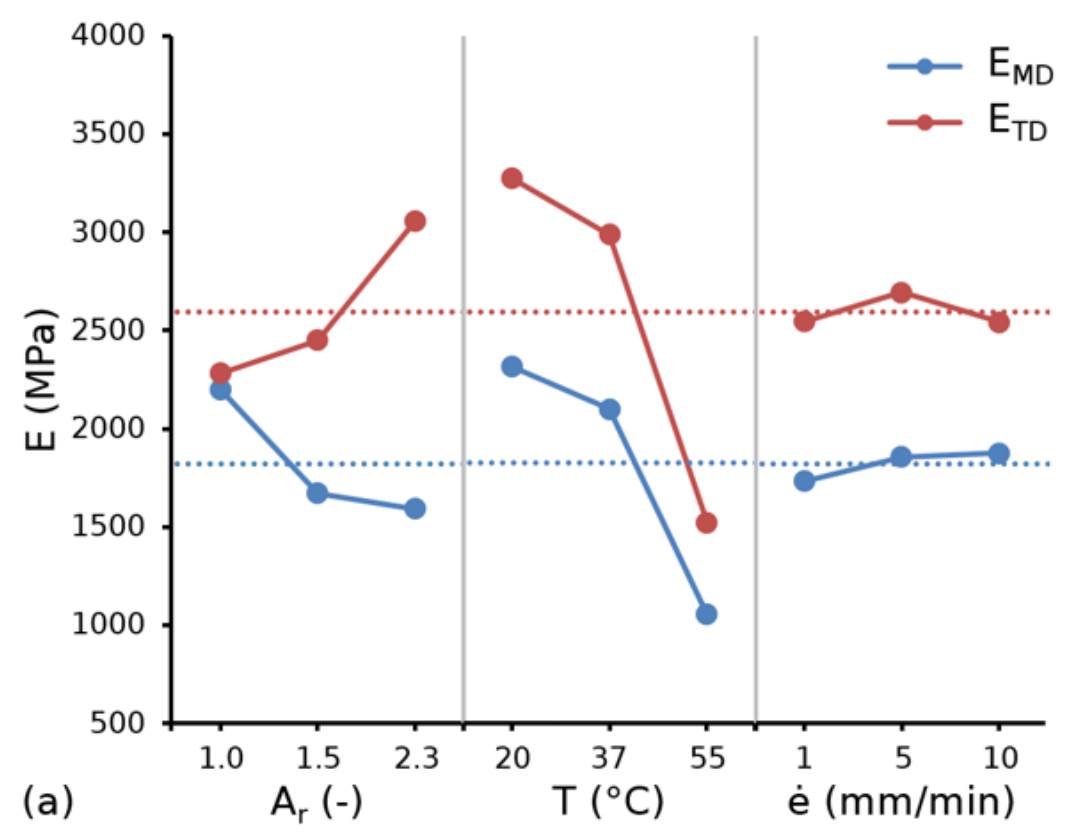

221

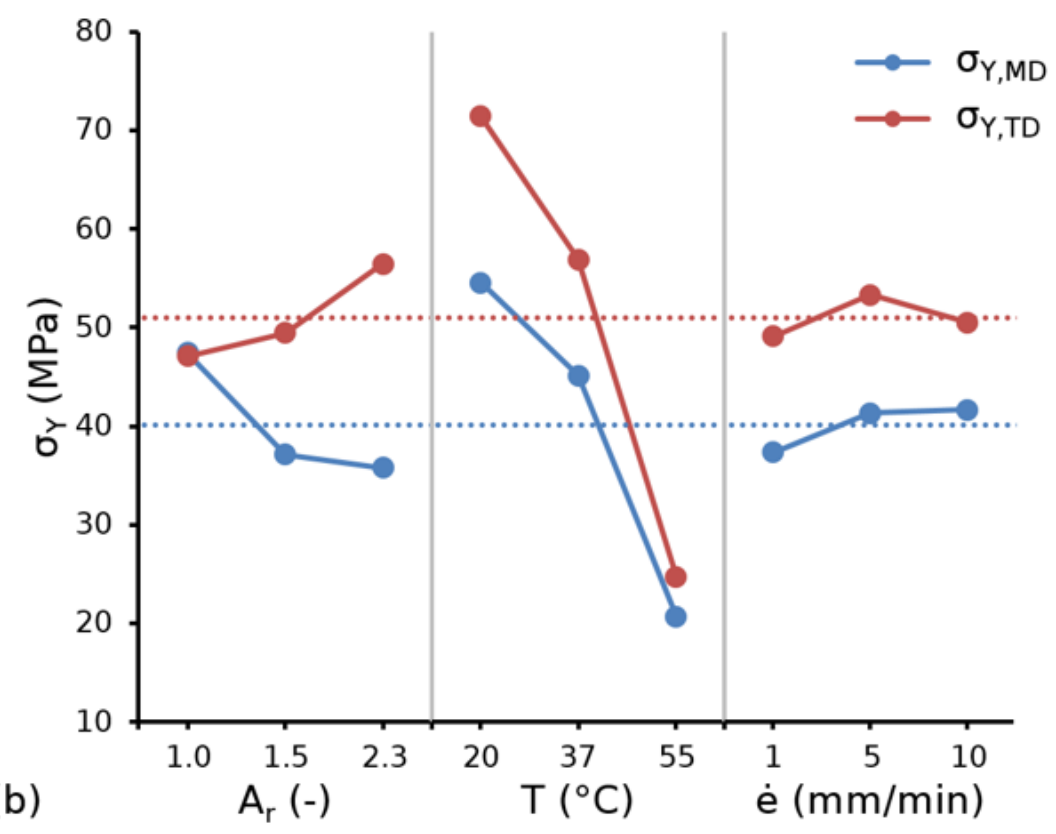

222 Fig. 3. Main effect plots highlighting the influence of the aspect ratio $\left(A_{r}\right)$ of the biaxial deformation, 223 post-processing temperature $(\mathrm{T})$ and post-processing extension rate (è) on (a) the elastic modulus (E) 224 of biaxially stretched PLLA sampled from the MD and the TD, $E_{M D}$ and $E_{T D}$, respectively; and (b) the 225 yield strength $\left(\sigma_{\mathrm{Y}}\right)$ in the MD and the TD, i.e. $\sigma_{\mathrm{Y}, \mathrm{MD}}$ and $\sigma_{\mathrm{Y}, \mathrm{TD}}$, respectively. 

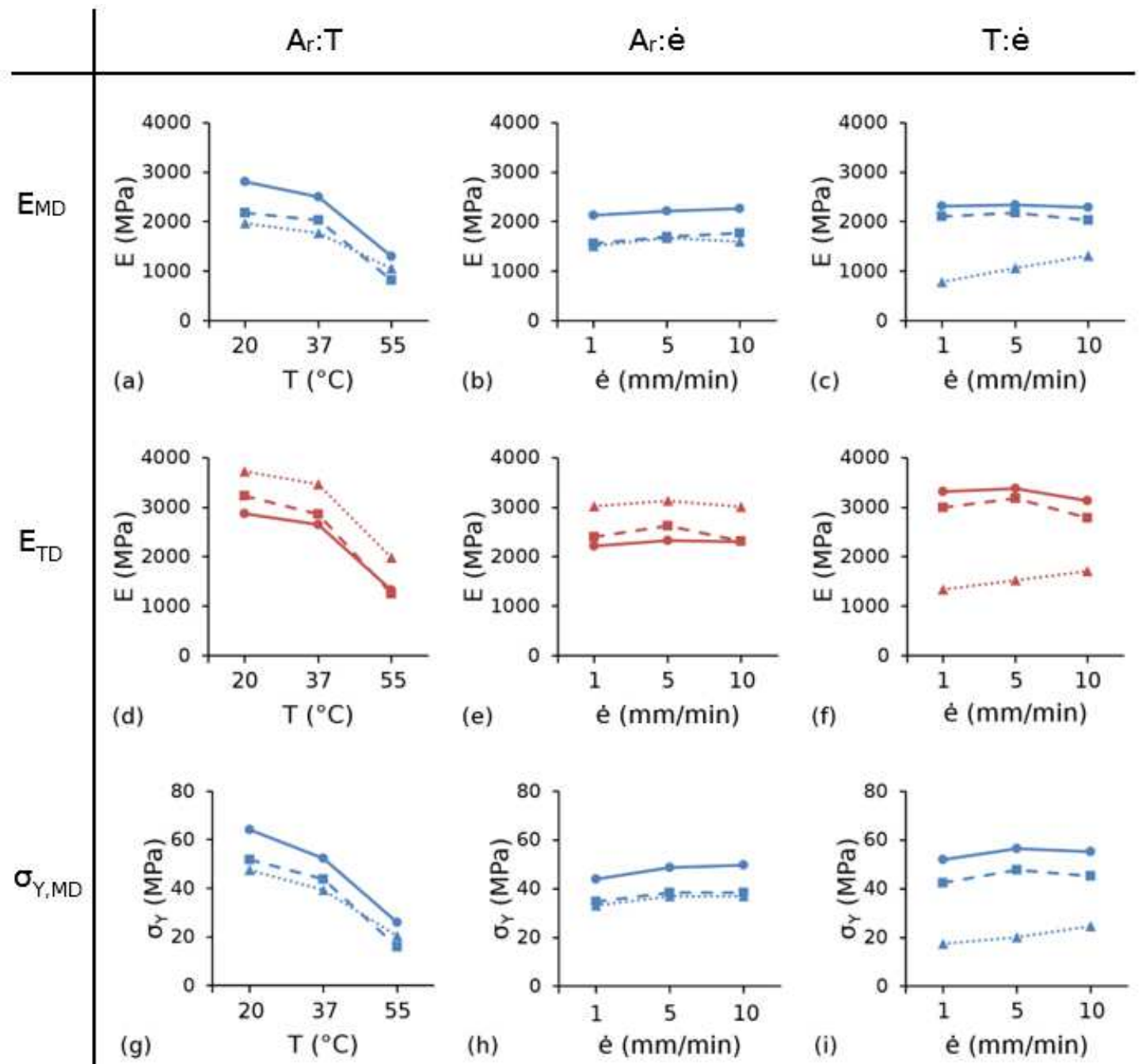

(g)

(h)
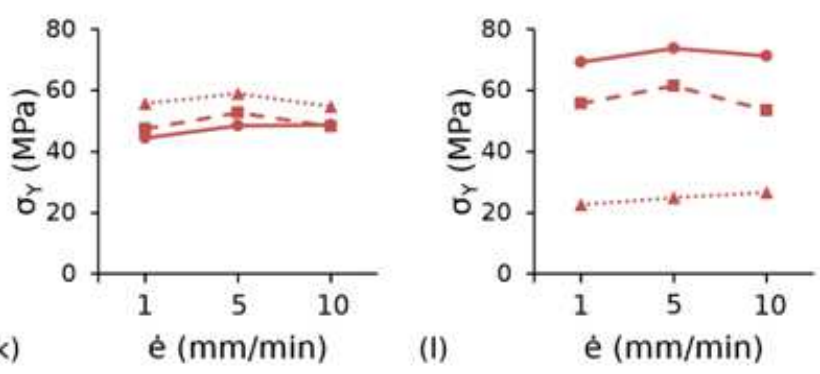

(j)

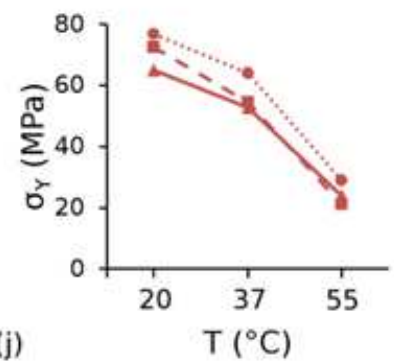

(k)

$$
\begin{aligned}
& \rightarrow-A_{r}=1 \\
& -\rightarrow-A_{r}=1.5 \\
& \cdots \cdot A_{r}=2.3
\end{aligned}
$$$$
\begin{aligned}
\rightarrow-\mathrm{T} & =20^{\circ} \mathrm{C} \\
-\rightarrow-\mathrm{T} & =37^{\circ} \mathrm{C} \\
\cdots \cdot \mathrm{T} & =55^{\circ} \mathrm{C}
\end{aligned}
$$

227 Fig. 4. Two-way interaction plots of the aspect ratio $\left(A_{r}\right)$ of the biaxial deformation, post-processing

228 temperature $(T)$ and post-processing extension rate $(\dot{e})$ on the elastic modulus $(E)$ in the $M D, E_{M D}$;

229 elastic modulus in the TD, $\mathrm{E}_{\mathrm{TD}}$; yield strength $\left(\sigma_{\mathrm{Y}}\right)$ in the $\mathrm{MD}, \sigma_{\mathrm{Y}, \mathrm{MD}}$ and yield strength in the TD, $\sigma_{\mathrm{Y}, \mathrm{TD}}$. 
Table 3. Maximum percentage increase in the storage modulus $\left(E^{\prime}\right)$ of biaxially stretched PLLA, sampled in the MD and the TD, during DMA frequency sweeps between $0.1 \mathrm{~Hz}$ and $10 \mathrm{~Hz}$, at various temperatures for a given aspect ratio $\left(A_{r}\right)$ of the biaxial deformation.

\begin{tabular}{|c|c|c|c|c|c|c|}
\hline \multirow[t]{2}{*}{$A_{r}(-)$} & \multicolumn{3}{|c|}{$\Delta E_{M D}^{\prime}(\%)$} & \multicolumn{3}{|c|}{$\Delta E_{T D}^{\prime}(\%)$} \\
\hline & $20^{\circ} \mathrm{C}$ & $37^{\circ} \mathrm{C}$ & $55^{\circ} \mathrm{C}$ & $20^{\circ} \mathrm{C}$ & $37^{\circ} \mathrm{C}$ & $55^{\circ} \mathrm{C}$ \\
\hline 1.0 & 1.6 & 2.6 & 3.4 & 1.4 & 2.4 & 3.0 \\
\hline 1.5 & 1.7 & 2.1 & 2.7 & 1.6 & 1.7 & 3.0 \\
\hline 2.3 & 1.4 & 1.7 & 2.2 & 1.4 & 1.3 & 2.5 \\
\hline
\end{tabular}

Since $E$ and $\sigma_{Y}$ were both affected by $A_{r}$ and $T$ but were insensitive to $\dot{e}$, a rate-independent, transversely isotropic, temperature-dependent, elastic-plastic constitutive model was used to capture the mechanical response of PLLA. The linear elastic material behaviour was assumed to be transversely isotropic, which implies that at each point within the material there exists an axis of rotational symmetry that is normal to a plane of isotropy (Staab, 2015). In transversely isotropic materials, there exists a plane in which the material properties are the same in all directions (plane

241 of isotropy) perpendicular to the plane's normal vector (axis of transverse isotropy). However, material properties differ in the axis of transverse isotropy relative to the plane of isotropy (Fig. 5). 


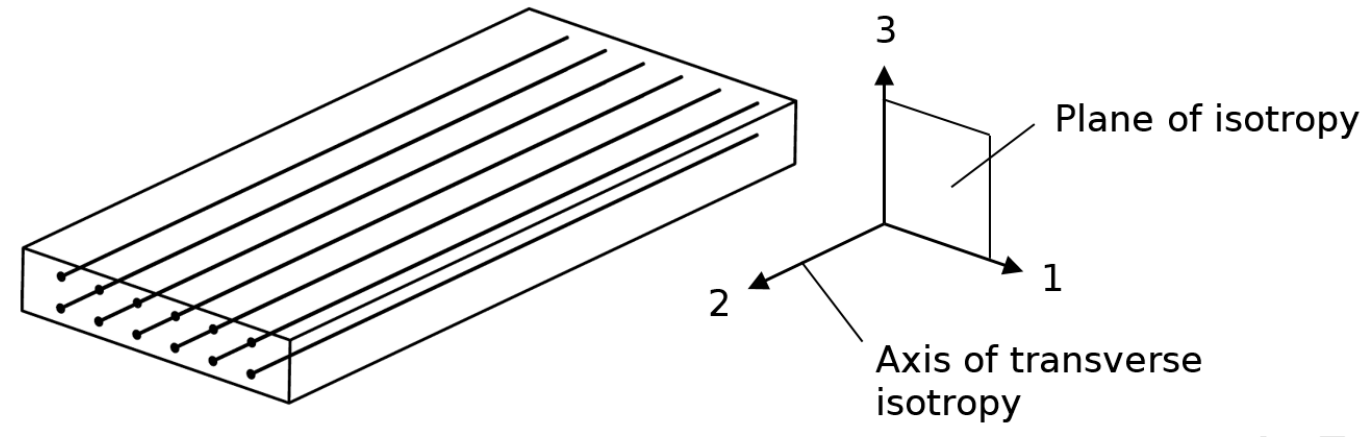

244 Fig. 5. Three-dimensional model of transverse isotropy for biaxially stretched sheet. The 1-3 plane represents the plane of isotropy, whilst the 2 axis represents the axis of transverse isotropy. The material properties are identical in the 1 and 3 axis directions but are different in the 2 axis direction.

Considering a Cartesian coordinate system, in which the principal directions are denoted using 1, 2 and 3 , and assuming the 1-3 plane to represent the plane of transverse isotropy, the generalised Hooke's law may be simplified to Eq. 6 (Cho et al., 2012; Hibbitt et al., 2016), where $\varepsilon$ denotes normal strain, $\gamma$ denotes shear strain, $\sigma$ denotes normal stress, $\tau$ denotes shear stress and the subscripts 1, 2 and 3 define direction. This equation is characterised by five independent elastic constants: $\mathrm{E}$ and $\mathrm{E}^{*}$ (representing the elastic moduli in the plane of transverse isotropy and in the direction normal to it, respectively), $v$ and $v^{*}$ (representing the Poisson's ratios characterising the lateral strain response in the plane of transverse isotropy to a stress acting parallel or normal to it, respectively), and $\mathrm{G}^{*}$ which represents the shear modulus in planes normal to the plane of isotropy (Amadei, 1996). However, using the Saint-Venant empirical approximation (Saint-Venant, 1863) in constants to four.

$$
\left\{\begin{array}{l}
\varepsilon_{11} \\
\varepsilon_{22} \\
\varepsilon_{33} \\
\gamma_{12} \\
\gamma_{13} \\
\gamma_{23}
\end{array}\right\}=\left[\begin{array}{cccccc}
1 / E & -v^{\prime} / E^{*} & -v / E & 0 & 0 & 0 \\
-v^{\prime} / E^{*} & 1 / E^{*} & -v^{\prime} / E^{*} & 0 & 0 & 0 \\
-v / E & -v^{\prime} / E^{*} & 1 / E & 0 & 0 & 0 \\
0 & 0 & 0 & 1 / G^{*} & 0 & 0 \\
0 & 0 & 0 & 0 & 2(1+v) / E & 0 \\
0 & 0 & 0 & 0 & 0 & 1 / G^{*}
\end{array}\right]\left\{\begin{array}{l}
\sigma_{11} \\
\sigma_{22} \\
\sigma_{33} \\
\tau_{12} \\
\tau_{13} \\
\tau_{23}
\end{array}\right\}
$$




$$
\frac{1}{G^{*}}=\frac{1}{E}+\frac{1}{E^{*}}+2 \frac{\nu^{*}}{E^{*}}
$$

260

261

262 263 stress (Eq. 15) (Hibbitt et al., 2016).

$$
\begin{aligned}
& f(\sigma)=\sqrt{\alpha_{1}\left(\sigma_{22}-\sigma_{33}\right)^{2}-\alpha_{2}\left(\sigma_{33}-\sigma_{11}\right)^{2}+\alpha_{3}\left(\sigma_{11}-\sigma_{22}\right)^{2}+2 \alpha_{4} \sigma_{23}{ }^{2}+2 \alpha_{5} \sigma_{31}{ }^{2}+2 \alpha_{6} \sigma_{12}{ }^{2}} \\
& \alpha_{1}=\frac{1}{2}\left(\frac{1}{r_{22}^{2}}+\frac{1}{r_{33}^{2}}-\frac{1}{r_{11}^{2}}\right) \\
& \alpha_{3}=\frac{1}{2}\left(\frac{1}{r_{11}^{2}}+\frac{1}{r_{22}^{2}}-\frac{1}{r_{33}^{2}}\right) \\
& \alpha_{5}=\frac{3}{2 r_{13}^{2}} \\
& r_{i j}= \begin{cases}\frac{\sigma_{i j}}{\sigma_{Y}} & \text { if } i=j \\
\frac{\sqrt{3} \sigma_{i j}}{\tau_{Y}} & \text { if } i \neq j\end{cases} \\
& \alpha_{2}=\frac{1}{2}\left(\frac{1}{r_{33}^{2}}+\frac{1}{r_{11}^{2}}-\frac{1}{r_{22}^{2}}\right) \\
& \alpha_{4}=\frac{3}{2 r_{23}^{2}} \\
& \alpha_{6}=\frac{3}{2 r_{12}^{2}}
\end{aligned}
$$

264

In the above equations, $\sigma_{\mathrm{ij}}$ is a non-zero stress component, $\sigma_{\mathrm{Y}}$ is the reference uniaxial yield strength

265 and $\tau_{Y}$ is the reference uniaxial shear yield strength.

The directional properties were defined such that MD, TD, and the through-thickness, or Z-direction (ZD) correspond to the 1, 2 and 3 directions. The MD-ZD plane therefore represents the plane of transverse isotropy, whilst TD represents the direction normal to the plane of isotropy. With respect to Eq. 6, the moduli may be written as $E=E_{M D}$ and $E^{*}=E_{T D}$, and calculated using Eq. 2 and Eq. 3. The Poisson's ratios characterising the lateral strain response in the plane of transverse isotropy to a stress acting parallel or normal to it, $v$ and $v^{*}$, were both assigned a value of 0.35 , based on typical datasheet specifications for PLLA (Farah et al., 2016). The yield strength ratios in the plane of transverse isotropy (in the MD and the ZD) were set to unity $\left(r_{11}=r_{33}=1\right)$ and there was no anisotropy defined for any of the shear stresses $\left(r_{12}=r_{13}=r_{23}=1\right)$. The yield strength ratio in the TD 
piecewise linear hardening model was used to capture the behaviour of PLLA post-yielding through a series of stress-strain couples with the Ramer-Douglas-Peucker algorithm (Douglas and Peucker, 1973; Ramer, 1972) used to reduce the number of data points whilst preserving the shape of the stress-strain curve.

Constitutive model calibration was performed using Python (version 2.7.13) (Python Software Foundation, 2018) and Abaqus/Standard 2016 (Dassault Systèmes, USA). A unit cube finite element simulation was performed in which the cube, assigned the custom constitutive model, was subjected to a pure uniaxial deformation (in both the MD and TD), a method commonly employed within the field of constitutive modelling (Bergström, 2015; Cowin, 2013; Yeoh, 1993). The residual sum of squares was used to provide a quantitative comparison between experimental data and simulation data using the NumPy (version 1.14.2) package (Oliphant, 2006), while the Matplotlib (version 2.2.2) package (Hunter, 2007) was used to provide a qualitative, visual assessment of the goodness of fit. The constitutive model was calibrated using uniaxial tensile test data (at an extension rate of $5 \mathrm{~mm} / \mathrm{min}$ ) for samples punched from biaxially stretched sheet in the MD and the TD, for all permutations of $A_{r}$ and T under the DOE (Fig. 6). It should be noted that an $A_{r}$ of 1 produced nearly identical stress-strain curves in the MD and the TD for all values of T. As a result, the constitutive model was calibrated to the TD experimental data and the model parameters were defined such that the material behaved isotropically for these cases $\left(E_{M D}=E_{T D}\right.$ and $\left.r_{11}=r_{22}=1\right)$. 


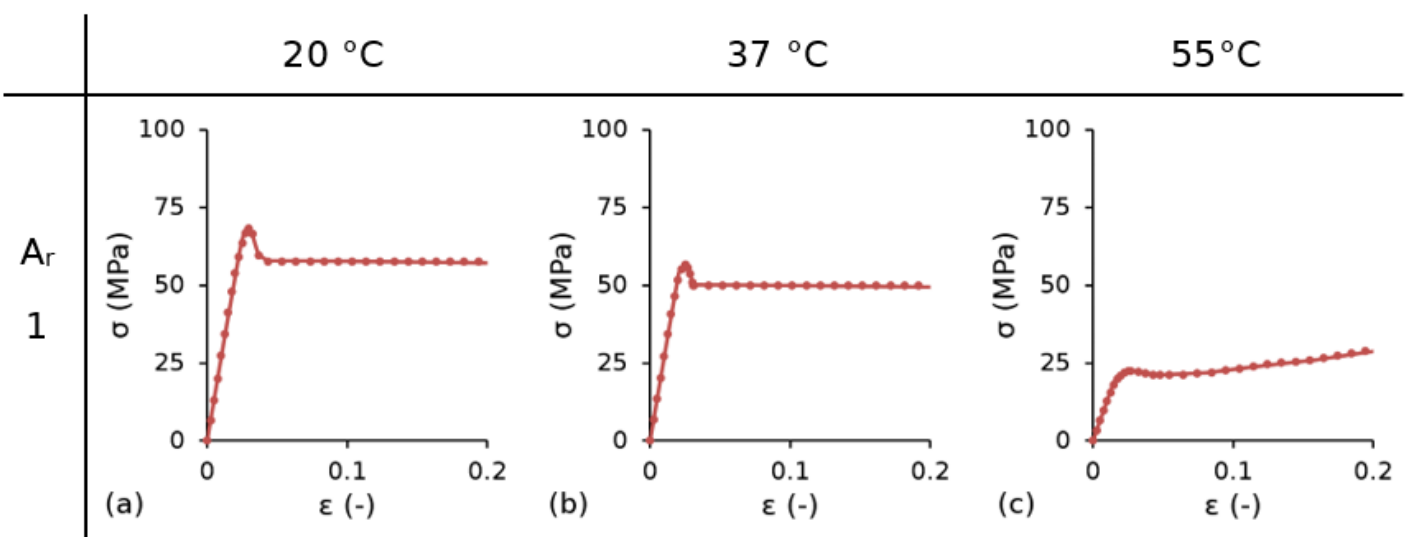

(a)

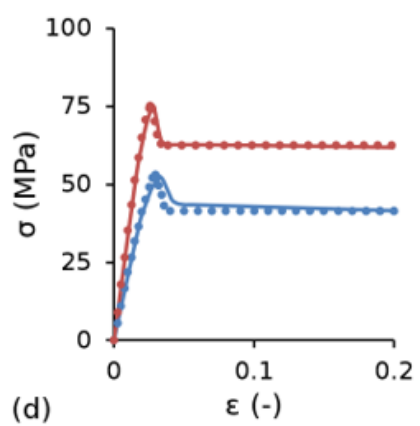

(d)

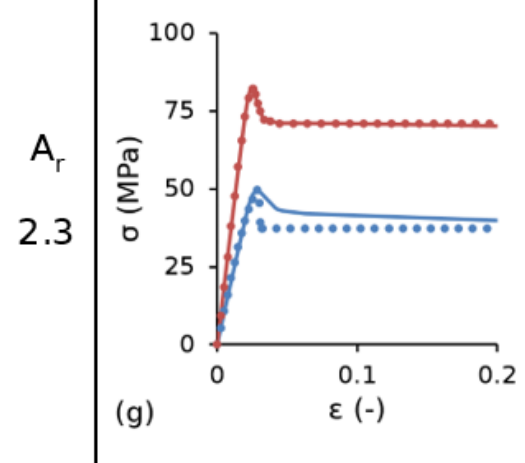

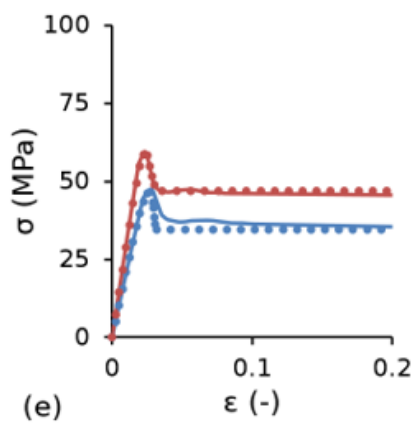

(e)

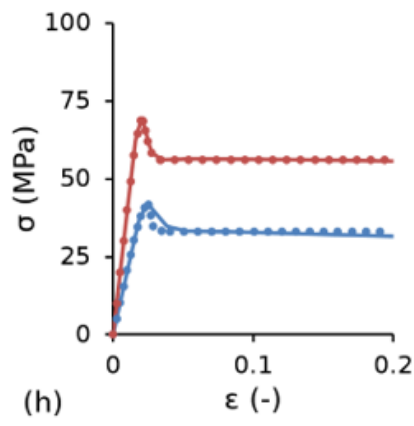

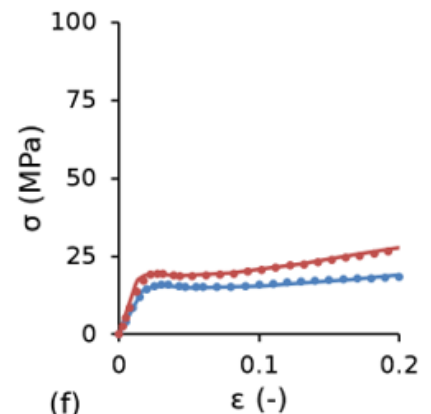

(f)

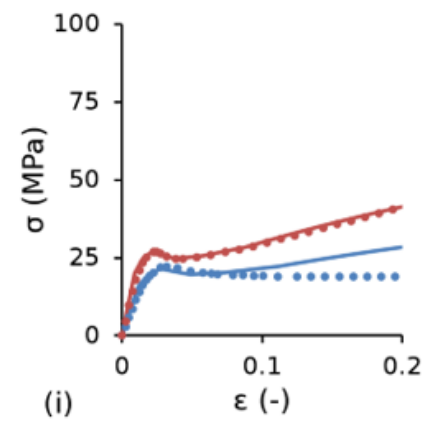

- Expt. TD - Expt. MD - Sim. TD -Sim. MD

295 Fig. 6. Comparison of experimental (expt.) data to simulation (sim.) prediction using the transversely 296 isotropic, temperature-dependent constitutive model. Nominal stress-strain $(\sigma-\varepsilon)$ plots are shown 297 for various aspect ratios $\left(A_{r}\right)$ and post-processing temperatures $(T)$ for biaxially stretched PLLA sampled from the MD and the TD, tested at an extension rate of $5 \mathrm{~mm} / \mathrm{min}$. 
299

300

301

302

303

304

305

306

307

308

309

310

311

312

313

314

315

316

317

318

319

\section{Discussion}

In this study, the effect of biaxial processing history, along with the effects of temperature and extension rate (post-processing) on the short-term (pre-degradation) mechanical properties of biaxially stretched PLLA were evaluated. Subsequently, a transversely isotropic, temperaturedependent constitutive model was calibrated to the experimental data. Given that a PLLA stent is exposed to different processing techniques, temperatures, and environmental conditions during its lifecycle, calibrating a representative material model that may be used during preclinical simulation has the potential to facilitate the design of high stiffness, thin-strut polymeric stents.

The DMA results show that the $T_{\mathrm{g}}$ is dependent on frequency, often referred to as dynamic transition (Gracia-Fernández et al., 2010). Dynamic transitions are commonly observed for semi-crystalline polymers, which generally see an increase in the $T_{g}$ as the test frequency is increased (Menard, 2008). The patented method for crimping a polymeric stent onto a delivery balloon (Jow et al., 2017) states crimping should occur at a temperature between the lowest measured $\mathrm{T}_{\mathrm{g}}\left(\mathrm{T}_{\mathrm{g}}-\mathrm{low}\right)$ and $15{ }^{\circ} \mathrm{C}$ below the $T_{\mathrm{g}}$-low. However, given the dynamic nature of the $T_{\mathrm{g}}$, care should be taken to match the crimping temperature to the time-scale of the procedure and, by extension, the rate of deformation. As the rate of deformation is decreased, the $\mathrm{T}_{\mathrm{g}}$ will decrease and the undesirable situation may arise whereby the crimping temperature exceeds the $T_{g}$ of the polymer, inducing significant changes in the polymer's molecular orientation and reducing its mechanical integrity (Jow et al., 2017).

Tensile test data showed that the mechanical response of PLLA is highly dependent on the aspect ratio of the biaxial deformation and the post-processing temperature. However, it was relatively insensitive to the post-processing extension rate. An increased elastic modulus and yield strength in the TD were obtained by increasing the aspect ratio of the biaxial deformation, at the expense of these properties in the MD. This improvement in mechanical properties was attributed to the degree of amorphous orientation induced during processing (Blair et al., 2018; Løvdal et al., 2015). The processing history had a stronger influence on the modulus than the yield strength; as the aspect 
ratio of the biaxial deformation was increased from 1 to $2.3, \mathrm{E}_{\mathrm{MD}}$ and $\mathrm{E}_{\mathrm{TD}}$ resulted in a $28 \%$ decrease

and $34 \%$ increase, respectively, compared to the respective $25 \%$ decrease and $20 \%$ increase in $\sigma_{\mathrm{Y}, \mathrm{MD}}$

and $\sigma_{\mathrm{Y}, \mathrm{TD}}$. In contrast, the post-processing temperature exhibited a stronger influence on the yield respective increase of $12 \%$ and $9 \%$ across the range of extension rates tested (i.e. $1-10 \mathrm{~mm} / \mathrm{min}$ ).

This is typical behaviour for semi-crystalline polymers and has been observed in many studies investigating the strain-rate-dependence of PLLA (Bobel et al., 2016; Debusschere et al., 2015; Eswaran et al., 2011). However, the influence of post-processing extension rate was considerably less than that of post-processing temperature and aspect ratio, given that no significant interactions were observed between post-processing extension rate and either post-processing temperature or aspect ratio. The results of DMA frequency sweeps were in agreement with the tensile test data and showed that the storage modulus remained relatively constant across the frequency range (i.e. 0.1$10 \mathrm{~Hz}$ ) at temperatures of 20,37 and $55^{\circ} \mathrm{C}$. Consequently, the polymer was idealised and assumed to be rate-independent across the range of strain rates tested (i.e. $10^{-4}-10^{-1} \mathrm{~s}^{-1}$ ) resulting in the calibration of a rate-independent, transversely isotropic, and temperature-dependent constitutive model.

The empirical relations (Eq. 2-5) and constitutive model presented herein may be used to augment the design and process optimisation of PLLA coronary stents. It is intended that during a PLLA stent's initial design phase, these empirical relations may be used as a computationally inexpensive method to evaluate the influence of the biaxial processing history on the mechanical 
performed parametric optimisation to refine the geometry of a stent (Bedoya et al., 2006; Li et al., 2017; Pant et al. 2012; Wu et al., 2008) or compared the influence of a particular material across common stent geometries (Bobel et al., 2015; Pauck and Reddy, 2015; Schultze et al., 2009). However, none of these studies considered the influence of biaxial stretching processing history and how it affects the design of the stent's geometry. One of the most challenging aspects to overcome in the design of polymeric-based stents lies in the significantly lower radial stiffness compared to their metallic counterparts, which is necessary to support the displaced arterial wall. By controlling the aspect ratio of the biaxial deformation and molecular orientation, it may be beneficial to process the stent such that the polymer has a preferential circumferential orientation. Matching the material processing to stent geometry through the use of the empirical relations and the constitutive model presented herein has the potential to generate polymeric stent designs with reduced strut thicknesses, suggesting an area for future investigation.

Although the constitutive model presented in this work incorporates the effects of temperature and processing parameters on the mechanical response of PLLA, there are limitations associated with the present study. The mode of deformation selected to calibrate the constitutive model was uniaxial and tensile, which is only partially representative of the mode of deformation that a typical coronary stent experiences during manufacture and in service. During both crimping and expansion, stent rings experience a combination of compression, tension and bending (Karanasiou et al., 2017; Migliavacca et al. 2005) that may not be adequately captured by the constitutive model presented herein. Additionally, the plastic portion of the constitutive model was calibrated to the TD experimental data and scaled to fit the MD experimental data through yield strength ratios. This resulted in the TD simulated stress-strain curves closely matching the TD experimental data for all aspect ratio and temperature combinations (Fig. 6). However, whenever there was a change in the gradient of the plastic portion of the stress-strain curves between the MD and the TD, the MD simulated stress-strain curves tended to deviate from the MD experimental data, as evident in Fig. 6i. Finally, stents may experience strains up to 50\% during crimping and deployment (Bobel et al., 
2016); however, nearly all of the samples in the present study fractured prior to this level of strain being reached. The introduction of a biocompatible plasticiser (e.g. polyethylene glycol) in a concentration of approximately $10-20 \% \mathrm{w} / \mathrm{w}$ with the PLLA has been shown to increase elongation beyond this threshold whilst maintaining a high degree of stiffness and strength (Farah et al., 2016; Martin and Avérous, 2001; Shibata et al., 2007). Alternatively, annealing at temperatures close to the $\mathrm{T}_{\mathrm{g}}$ promotes a brittle-to-ductile change in the fracture behaviour of PLLA and increases elongation-to-break with minimal reduction in mechanical properties (Kfoury et al., 2013). Given that biaxial deformation increases elongation-to-break compared to the unstretched PLLA (Wu et al., 2013), it is hypothesised that combining annealing with the introduction of a plasticiser could produce a polymer that is capable of consistently achieving these strain levels, suggesting an area for future work.

\section{Conclusion}

Results of an extensive experimental programme to characterise the post-processing material properties of PLLA indicated that the elastic modulus and yield strength of the biaxially stretched sheets were strongly influenced by the aspect ratio during biaxial deformation and post-processing temperature. In contrast, post-processing extension rate had relatively little influence on these mechanical properties. A transversely isotropic, temperature-dependent constitutive model was calibrated against experimental data using equations that relate the elastic modulus and yield strength of biaxially stretched sheets to the aspect ratio during processing and post-processing temperature (during uniaxial deformation). The constitutive model proposed in this study could potentially be used during preclinical simulation to facilitate the optimal design of high stiffness, thin-strut polymeric stents that contend with the performance of their metallic counterparts. 
399 The authors wish to acknowledge funding from the Engineering and Physical Sciences Research 400 Council (EPSRC) (S3804ASA) and the Marie Skłodowska-Curie Research and Innovation Staff 401 Exchange (RISE), grant agreement 691238. The authors also wish to acknowledge the research 402 institutions involved in the Bi-Stretch-4-Biomed collaborative research project (California Institute of 403 Technology, University of Warwick and ENEA: Italian National Agency for New Technologies, Energy 404 and Sustainable Economic Development). Uniaxial tensile and DMA testing were performed under 405 the supervision of Dr Bronagh Millar and Dr Paula Douglas through the Polymer Processing Research 406 Centre at QUB. 
407

408

409

410

411

412

413

414

415

416

417

418

419

420

421

422

423

424

425

426

427

428

429

430

431

432

433

\section{References}

Abbott, 2012. Absorb Bioresorbable Vascular Scaffold System, Abbott Vascular, 3200 Lakeside Drive, Santa Clara, CA 95054-2807, USA.

Alexy, R. D. and Levi, D. S., 2013. Materials and manufacturing technologies available for production of a pediatric bioabsorbable stent. BioMed Research International 2013, 2013.

Amadei, B., 1996. Importance of anisotropy when estimating and measuring in situ stresses in rock. International Journal of Rock Mechanics and Mining Sciences \& Geomechanics Abstracts, 33(3):293325.

Bedoya, J., Meyer, C. A., Timmins, L. H., Moreno, M. R. and Moore, J. E., 2006. Effects of stent design parameters on normal artery wall mechanics. Journal of Biomechanical Engineering, 128(5):757-765.

Bergström, J. S., 2015. Mechanics of solid polymers: theory and computational modeling. William Andrew.

Bergström, J. S. and Hayman, D., 2015. An overview of mechanical properties and material modeling of polylactide (PLA) for medical applications. Annals of Biomedical Engineering, 44(2):330-340.

Blair, R. W., Dunne, N. J., Lennon, A. B. and Menary, G. H., 2018. Processing-property relationships of biaxially stretched poly(L-lactic acid) sheet for application in coronary stents. Journal of the Mechanical Behavior of Biomedical Materials, 86:113-121.

Bobel, A. C. and McHugh, P. E., 2018. Computational Analysis of the Utilisation of the Shape Memory Effect and Balloon Expansion in Fully Polymeric Stent Deployment. Cardiovascular Engineering and Technology, 9(1):60-72.

Bobel, A. C., Lohfeld, S., Shirazi, R. N. and McHugh, P. E., 2016. Experimental mechanical testing of Poly (I-Lactide) (PLLA) to facilitate pre-degradation characteristics for application in cardiovascular stenting. Polymer Testing, 54:150-158.

Bobel, A. C., Petisco, S., Sarasua, J. R., Wang, W. and McHugh, P. E., 2015. Computational bench testing to evaluate the short-term mechanical performance of a polymeric stent. Cardiovascular Engineering and Technology, 6(4):519-532. 
Bourantas, C. V., Onuma, Y., Farooq, V., Zhang, Y., Garcia-Garcia, H. M., and Serruys, P. W., 2013.

Bioresorbable Scaffolds: Current Knowledge, Potentialities and Limitations Experienced During their

Brie, D., Penson, P., Serban, M. C., Toth, P. P., Simonton, C., Serruys, P. W. and Banach, M., 2016. Bioresorbable scaffold-A magic bullet for the treatment of coronary artery disease? International Journal of Cardiology, 215:47-59.

Ui, S., Chino, M. and Isshiki, T., 2005. Rates of primary percutaneous coronary intervention worldwide. Circulation Journal, 69(1):95-100.

Cho, J. W., Kim, H., Jeon, S. and Min, K. B., 2012. Deformation and strength anisotropy of Asan gneiss, Boryeong shale, and Yeoncheon schist. International Journal of Rock Mechanics and Mining Sciences, 50:158-169.

Cowin, S. C., 2013. Continuum mechanics of anisotropic materials. Springer Science \& Business Media.

Debusschere, N., Segers, P., Dubruel, P., Verhegghe, B. and De Beule, M., 2015. A finite element strategy to investigate the free expansion behaviour of a biodegradable polymeric stent. Journal of Biomechanics, 48(10):2012-2018.

Douglas, D. H. and Peucker, T. K., 1973. Algorithms for the reduction of the number of points required to represent a digitized line or its caricature. Cartographica: The International Journal for Geographic Information and Geovisualization, 10(2):112-122.

Eswaran, S. K., Kelley, J. A., Bergstrom, J. S. and Giddings, V. L., 2011. Material modeling of polylactide. Proceedings of the SIMULIA Customer Conference, pp. 1-11.

Farah, S., Anderson, D. G., and Langer, R., 2016. Physical and mechanical properties of PLA, and their functions in widespread applications-A comprehensive review. Advanced Drug Delivery Reviews, 107:367-392.

Grabow, N., Schlun, M., Sternberg, K., Hakansson, N., Kramer, S. and Schmitz, K. P., 2005. Mechanical properties of laser cut poly (L-lactide) micro-specimens: implications for stent design, manufacture, and sterilization. Journal of biomechanical engineering, 127(1):25-31.

461 Gracia-Fernández, C. A., Gómez-Barreiro, S., López-Beceiro, J., Saavedra, J. T., Naya, S. and Artiaga, 462 R., 2010. Comparative study of the dynamic glass transition temperature by DMA and TMDSC. Polymer Testing, 29(8):1002-1006. 
Hayman, D., Bergerson, C., Miller, S., Moreno, M. and Moore, J. E., 2014. The effect of static and dynamic loading on degradation of PLLA stent fibers. Journal of Biomechanical Engineering, 136(8):081006.

Hibbitt, H., Karlsson, B. and Sorensen, P., 2016. Abaqus Analysis User's Manual Version 2016. Dassault Systèmes Simulia Corp, Providence, USA.

Hill, R., 1948. A theory of the yielding and plastic flow of anisotropic metals. Proceedings of the Royal Society of London A, 193(1033), pp. 281-297.

Hunter, J. D., 2007. Matplotlib: A 2D Graphics Environment, Computing in Science \& Engineering, 9:90-95.

Jow, K. F., Yang, A. S., Wang, Y., \& Yan, K. W., 2017. U.S. Patent No. 9,757,897B2. Methods for crimping a polymeric stent onto a delivery balloon, Washington, DC: U.S. Patent and Trademark Office.

Karanasiou, G. S., Papafaklis, M. I., Conway, C., Michalis, L. K., Tzafriri, R., Edelman, E. R. and Fotiadis, D. I., 2017. Stents: biomechanics, biomaterials, and insights from computational modeling. Annals of biomedical engineering, 45(4):853-872.

Khan, K. A. and El-Sayed, T., 2013. A phenomenological constitutive model for the nonlinear viscoelastic responses of biodegradable polymers. Acta Mechanica, 224(2):287-305.

Kfoury, G., Raquez, J. M., Hassouna, F., Odent, J., Toniazzo, V., Ruch, D. and Dubois, P., 2013. Recent advances in high performance poly (lactide): from "green" plasticization to super-tough materials via (reactive) compounding. Frontiers in Chemistry, 1:1-46.

Lally, C., Dolan, F. and Prendergast, P. J., 2005. Cardiovascular stent design and vessel stresses: a finite element analysis. Journal of biomechanics, 38(8):1574-1581.

Li, H., Wang, X., Wei, Y., Liu, T., Gu, J., Li, Z., Wang, M., Zhao, D., Qiao, A. and Liu, Y., 2017. MultiObjective Optimizations of Biodegradable Polymer Stent Structure and Stent Microinjection Molding Process. Polymers, 9(1):20.

Lim, L. T., Auras, R. and Rubino, M., 2008. Processing technologies for poly (lactic acid). Progress in Polymer Science, 33(8):820-852. 
Ludman, P. and Gavalova, L., 2016. National Audit of Percutaneous Coronary Interventions Annual Public Report, Jan 2015 to Dec 2015. British Cardiovascular Intervention Society. Retrieved from: https://www.hqip.org.uk [Accessed 26 June 2018].

Martin, P. J., Tan, C. W., Tshai, K. Y., McCool, R., Menary, G., Armstrong, C. G. and Harkin-Jones, E.

M. A., 2005. Biaxial characterisation of materials for thermoforming and blow moulding. Plastics, Rubber and Composites, 34(5-6):276-282.

Martin, O. and Averous, L., 2001. Poly (lactic acid): plasticization and properties of biodegradable multiphase systems. Polymer, 42(14):6209-6219.

501

Menard, K. P., 2008. Dynamic Mechanical Analysis: A Practical Introduction. CRC press. predictive study of the mechanical behaviour of coronary stents by computer modelling. Medical Engineering and Physics, 27(1):13-18.

Muliana, A. and Rajagopal, K. R., 2012. Modeling the response of nonlinear viscoelastic biodegradable polymeric stents. International Journal of Solids and Structures, 49(7-8):989-1000.

Oliphant, T. E, 2006. A guide to NumPy, USA: Trelgol Publishing. Retrieved from: http:www.numpy.org [Accessed 5 Dec. 2018].

Ottosen, N. S. and Ristinmaa, M., 2005. The Mechanics of Constitutive Modeling. Elsevier, 510 Amsterdam.

511 Pant, S., Bressloff, N. W., and Limbert, G., 2012. Geometry parameterization and multidisciplinary 512 constrained optimization of coronary stents. Biomechanics and Modeling in Mechanobiology, 11(1$5132): 61-82$.

514 Pauck, R. G. and Reddy, B. D., 2015. Computational analysis of the radial mechanical performance of PLLA coronary artery stents. Medical Engineering and Physics, 37(1):7-12.

Python Software Foundation, 2018. The Python Language Reference. Retrieved from:

517 http://www.python.org [Accessed 5 Dec. 2018].

518 R Core Team, 2017. R: A Language and Environment for Statistical Computing, $R$ Foundation for 519 Statistical Computing, Vienna, Austria. Retrieved from: https://www.r-project.org [Accessed 5 Dec. 520 2018]. 
Ramer, U., 1972. An iterative procedure for the polygonal approximation of plane curves. Computer Graphics and Image Processing, 1(3):244-256.

Ross, R., 1999. Atherosclerosis-an inflammatory disease. New England Journal of Medicine, 340(2):115-126.

Saint-Venant, B., 1863. Sur la distribution des élasticités autour de chaque point d'un solide ou d'un milieu de contexture quelconque, particulièrement lorsqu'il est amorphe sans être isotrope. Journal de Math Pures et Appliquées, 7-8:353-430 [257-261 (In French)].

Schultze, C., Grabow, N., Martin, H. and Schmitz, K. P., 2009. Finite-element-analysis and in vitro study of bioabsorbable polymer stent designs. In Proceedings of the $4^{\text {th }}$ European Conference of the International Federation for Medical and Biological Engineering, pp. 2175-2178.

Serruys, P. W., Onuma, Y., Dudek, D., Smits, P. C., Koolen, J., Chevalier, B., de Bruyne, B., Thuesen, L., McClean, D., van Geuns, R.J. and Windecker, S., 2011. Evaluation of the second generation of a bioresorbable everolimus-eluting vascular scaffold for the treatment of de novo coronary artery stenosis: 12-month clinical and imaging outcomes. Journal of the American College of Cardiology, 58(15):1578-1588.

Shibata, M., Teramoto, N. and Inoue, Y., 2007. Mechanical properties, morphologies, and crystallization behavior of plasticized poly (L-lactide)/poly (butylene succinate-co-L-lactate) blends. Polymer, 48(9):2768-2777.

Soares, J. S., Moore Jr, J. E. and Rajagopal, K. R., 2008. Constitutive framework for biodegradable polymers with applications to biodegradable stents. Asaio Journal, 54(3):295-301.

Staab, G., 2015. Laminar composites. Butterworth-Heinemann.

Tada, T., Byrne, R.A., Simunovic, I., King, L.A., Cassese, S., Joner, M., Fusaro, M., Schneider, S., Schulz, S., Ibrahim, T. and Ott, I., 2013. Risk of stent thrombosis among bare-metal stents, firstgeneration drug-eluting stents, and second-generation drug-eluting stents: results from a registry of 18,334 patients. JACC: Cardiovascular Interventions, 6(12):1267-1274.

U S Food and Drug Administration, 2016. Reporting of Computational Modeling Studies in Medical Device Submissions-Draft Guidance for Industry and Food and Drug Administration Staff. Retrieved from: https://www.fda.gov [Accessed 25 Apr. 2018]. 
U S Food and Drug Administration, 2010. Non-Clinical Engineering Tests and Recommended Labeling

550 for Intravascular Stents and Associated Delivery Systems. Retrieved from: https://www.fda.gov/

551 [Accessed 25 Apr. 2018].

552 Wang, Q., Fang, G., Zhao, Y., Wang, G. and Cai, T., 2017. Computational and experimental 553 investigation into mechanical performances of Poly-L-Lactide Acid (PLLA) coronary stents. Journal of 554 the Mechanical Behavior of Biomedical Materials, 65:415-427.

555 Wiebe, J., Holger M. N. and Christian W. H., 2014. Current status of bioresorbable scaffolds in the 556 treatment of coronary artery disease. Journal of the American College of Cardiology, 557 64(23):2541-2551.

558 World Health Organization, 2017. Disease burden and mortality estimates: Summary tables of 559 mortality estimates by cause, age and sex, globally and by region, 2000-2016. Retrieved from: 560 http://www.who.int [Accessed 10 Sep. 2018].

561 World Health Organization, 2012. World Health Day 2012: ageing and health: toolkit for event 562 organizers. Retrieved from: http://www.who.int [Accessed 10 Sep. 2018].

563 Wu, J. H., Yen, M. S., Wu, C. P., Li, C. H. and Kuo, M. C., 2013. Effect of biaxial stretching on thermal 564 properties, shrinkage and mechanical properties of poly (lactic acid) films. Journal of Polymers and 565 the Environment, 21(1):303-311.

566 Wu, W., Yang, D. Z., Huang, Y. Y., Qi, M. and Wang, W. Q., 2008. Topology optimization of a novel 567 stent platform with drug reservoirs. Medical Engineering and Physics, 30(9):1177-1185.

568 Yeoh, O. H., 1993. Some forms of the strain energy function for rubber. Rubber Chemistry and 569 Technology, 66(5):754-771. 